\title{
THE EFFECT OF CODED AND NON-CODED CORRECTION FEEDBACK ON THE QUALITY OF INDONESIAN EFL STUDENTS' WRITING
}

\author{
Ali Saukah' \\ Desak Made Indah Dewanti \\ Ekaning Dewanti Laksmi ${ }^{3}$ \\ Universitas Negeri Malang, East Java, Indonesia ${ }^{1,3}$ \\ Bali Kiddy School, Bali, Indonesia ${ }^{2}$ \\ ali.saukah.fs@um.ac.id
}

First received: I3 March 2017

Final proof received: 25 September 2017

\begin{abstract}
Written corrective feedback (WCF) in L2 writing classrooms has gained considerable attention in applied linguistics research over the past twenty years. WCF may take different forms of teacher's responses to errors in students' texts, among others Coded-Correction Feedback (CCF) and NonCoded Correction Feedback (NCCF). A number of research studies on the effectiveness of various types of corrective feedback have been undertaken; however the effect of CCF and NCCF on the quality of students' writing in Indonesian context has not yet been explored. The objective of this study was to investigate the effects of Coded Correction Feedback and Non-Coded Correction Feedback on senior high school students' writing quality. This study investigated the effect of Coded-Correction Feedback (CCF) and Non-Coded Correction Feedback (NCCF) on the quality of Indonesian EFL students' writing. It involved 53 senior high school students of $11^{\text {th }}$ Grade. Each student was exposed to two different treatments (CCF and NCCF) and the students' writing quality, after receiving each type of treatments or WCF, was then measured. The effect of each feedback was estimated by comparing the individual students' scores in writing composition after receiving CCF with their scores after receiving NCCF. The result of this study revealed that the quality of the students' writing with CCF was better than that with NCCF. The findings of this study showed that the quality of the students' writing receiving CCF was better than that receiving NCCF because CCF promotes awareness with noticing as well as understanding. Hence, the use of CCF can be considered more effective than NCCF. Therefore, it is suggested that CCF be employed in giving corrective feedback to the students' compositions to improve the quality of their writing, and that teachers employ CCF when giving WCF to improve the quality of students' writing.
\end{abstract}

Keywords: corrective feedback; coded-correction feedback; non-coded correction feedback; quality of writing

Written corrective feedback (WCF) in L2 writing classrooms has gained considerable attention in applied linguistics research over the past twenty years. WCF or error correction may aid students' writing development and can be employed as a functional method for language learning. Findings from a number of studies support the use of corrective feedback in writing. A study by Bitchener (2008) reveals that the accuracy of students who receive written corrective feedback in the immediate post-test is better than that in the control group, and this level of performance is retained two months later after the treatment. Another study, conducted by Van Beuningen (2010), shows that corrective feedback fosters language learning and develops accuracy as it offers learners opportunities to notice the gaps in their linguistic systems, to test interlanguage hypotheses, and to be engaged in metalinguistic reflection. Confirming these two studies, the result of a study by Purnawarman (2011) suggests that providing teacher corrective feedback is effective in reducing students' grammatical errors on their essays. Further, as revealed by Ferris, Liu, Sinha, and Senna, (2013), students find the techniques of focused WCF, revision, and one-toone discussions about errors useful. Hence, corrective feedback provides positive effects toward students' writing.

Major learning theories-behaviorism, cognitive constructivism, and social constructivism - recognize feedback as an important aspect in learning and instruction. As Williams and Burden (1997) assert, behavioral view of learning sees reinforcement and feedback have important instructional effects on student learning. Similarly, cognitive constructivism places feedback as an essential element in language teaching as confirmed by a study involving university students by Baker and Bricker (2010) which reveals that learners were fast but not accurate in improving errors when they received indirect or hedging feedback and that learners were slow but accurate in improving errors 
when they received direct feedback. In addition, in a study involving secondary vocational education students, Van Beuningen, De Jong, and Kuiken (2012) showed that direct and indirect feedback led to fewer errors than self-correction or additional practice time. They also found that direct feedback was more appropriate for correcting grammar errors and that indirect feedback was more appropriate for correcting non-grammar errors. Likewise, feedback is recognized as having a profound effect on learning success. This notion is warranted in a study by Gielen, Peeters, Dochy, Onghena, and Struyven, (2010) concluding that justification feedback (i.e., an argumentation of, for instance, strengths) reinforces learning outcomes for low performing students and a study by Li, Liu, and Steckelberg (2010) finds a significant relationship between the quality of feedback (i.e., identification of central issues and constructive comments) and the quality of students' projects if controlled for students' initial projects. Furthermore, feedback is also an inherent part of Gagne's (1985) systematic instructional design model.

Following the important role of feedback in learning, Brown (2007) suggests that teachers should sensitively apply methods of responding to and correcting students' writing. Error correction in writing can begin in the drafting and revising stages, during which time it is more appropriate to consider errors. Carless (2006) also confirms that students who receive feedback during the writing process have a clearer sense of how well they perform and what they need to do to improve. In addition, feedback can also modify students' thinking or behavior toward their work and focus their attention on the purpose of writing.

WCF may take different forms of teacher's responses to errors in students' texts. Ellis, Loewen, and Erlam (2006) categorize these teacher's responses into three forms or strategies: (a) The teacher provides the student with the correct form (Direct CF); (b) The teacher indicates that an error exists but does not provide the correction (Indirect $\mathrm{CF}$ ); and (c) The teacher provides some kind of metalinguistic clue as to the nature of the error (Metalinguistic $\mathrm{CF}$ ). Indirect $\mathrm{CF}$ takes the form of underlining, circling and use of cursors to show omissions in the student's text (Muth'im \& Latief, 2014). This kind of feedback is also known as error location or Non-Coded Correction Feedback (NCCF). With the absence of any code, in order to be able to correct the incorrect performance of the language, the students should be able to identify what kind of errors they have made before they are able to correct the errors. On the other hand, in using Metalinguistic CF, the teacher writes codes in the margin (e.g. WW = wrong word; art = article). This kind of feedback is also known as error identification or Coded Correction Feedback (CCF). $\mathrm{CCF}$ is used with the theory that by being helped with the availability of codes to indicate errors, the students will be able to connect their memory to the area indicated by the code. Their prior knowledge is supposed to guide them to come to the right correction. This is in line with Krashen's (2003) Monitor Hypothesis theory which claims that if the students know the rule, they will be able to correct the incorrect production of language the performer must be consciously concerned about.

The findings of previous research reveal that both Coded Correction Feedback (CCF) and NonCoded Correction Feedback (NCCF) are effective to improve students' writing as shown by Hong (2004) who carried out a study on the effect of teachers' error feedback on international students' self correction ability by having three groups: $\mathrm{CCF}$, NCCF and control group. The findings of the research show that there is a statistically significant difference in students' self correction ability between the control group and the experimental groups ( $\mathrm{CCF}$ and NCCF). There is no significant difference in performance on self correction between NCCF and CCF group; however, survey results reveal that students preferred receiving $\mathrm{CCF}$ rather than NCCF. Another research was conducted by Muthi'm and Latief (2014). They implemented three kinds of correction feedback, namely sample end comment (SEC) feedback, coded correction feedback (CCF) and non-coded correction feedback (NCCF). This experimental study was intended to find out which correction feedback would give more effective result in the students' writing quality. The important finding was the different improvement of components of writing in essay writing components between CCF and NCCF groups. The group with $\mathrm{CCF}$ made progress in four components of writing: content, organization, vocabulary and mechanics. On the other hand, the group with NCCF made progress in content, organization, language use and mechanics.

Besides different forms of corrective feedback, the effects of written $\mathrm{CF}$ on short-term revision or long-term improvement also become issues raised in previous research studies. From both theoretical and practical perspective, the influence of written $\mathrm{CF}$ on short-term revision is an interesting and relevant issue (Bitchener \& Ferris, 2012). When students receive written $\mathrm{CF}$ on a text and are then asked to revise that text, they do so successfully, with "success" being defined as a statistically significant reduction in the number of errors from one draft to the next. When they do not receive written $\mathrm{CF}$, they are much less able and likely to correct errors on their own as supported by several research findings related to short term effect of written $\mathrm{CF}$ as confirmed by some studies in EFL context, e.g. a study by Ashwell (2000) and another study by Truscott and Hsu (2008). A study by Ferris \& Roberts (2001) reveals that ESL college students who received error feedback successfully revised 
more than 60 percent of their total errors and their correction ratio was significantly higher than a control group's ratio. A study of Ashwell (2000) involved 50 Japanese university students (EFL context) in four treatment groups in which three of the four received form-based feedback before revising their texts. The result shows that students who received form based feedback wrote significantly more accurate revised drafts than a control group receiving no feedback. Furthermore, in Truscott and Hsu (2008) study, 47 EFL graduate students were divided into two groups and the finding discovered that students in the experimental group significantly outperformed the control group in self-correcting errors during revision.

Several gaps regarding the previous research about written corrective feedback have been identified as a basis to conduct a new study. As most of the previous studies focused on partially learned linguistic features, there is a need to conduct a further research in regards to other grammatical items or other aspects of writing such as content, organization, vocabulary and mechanic (Bitchener, 2008). Therefore, the components of student's writing quality in this present study involved those aspects of writing. In the case of research of written CF on short-term effects, previous studies basically involved experiment and control group, without comparing the effect of different kinds of correction feedback (Ferris \& Roberts, 2001; Ashwell, 2000; Truscott \& Hsu, 2008). Further, although a number of studies were conducted regarding the use of Coded Correction Feedback (CCF), and Non-Coded Correction Feedback (NCCF), the present study differed in some ways. In Hong's study (2004), the dependent variable investigated was the ability of students in self-correction of their writing, whereas the present study was conducted to find the effect of correction feedback on the quality of students' writing. In addition, the research subjects in previous research studies (Ferris \& Roberts, 2001; Ashwell, 2000; Truscott \& Hsu, 2008; Hong, 2004; Muthi'm \& Latief, 2014) were adults or intermediate ESL learners of university level who produce academic essay. Hence, there is a need to do further research study involving different subjects in EFL context, such as senior high school students. Thus, the level of students and writing composition in this present study were different from previous studies.

The objective of this study was to investigate the effects of Coded Correction Feedback and NonCoded Correction Feedback on senior high school students' writing quality. The result of this study showed which of the correction feedback was a more effective method of giving written corrective feedback.

\section{METHOD}

This present study was conducted in one of the senior high schools in Singaraja, Bali, Indonesia. The population was the $11^{\text {th }}$ Grade students in the academic year of 2015/2016, the total number of which was 305 students. The participants of this study were 53 students taken from two randomly chosen classes.

The design of this study was the repeated measure design. In this design, each participant received both types of the treatment administered, and the writing quality of participant was measured after receiving each type of treatment. In this case, each participant received both types of correction feedback: Coded Correction Feedback (CCF) and Non-Coded Correction Feedback (NCCF). We estimated the effect of the independent variables (X) by comparing each participant's score in writing composition $\left(\mathrm{Y}_{1}\right)$ after receiving $\mathrm{CCF}\left(\mathrm{X}_{1}\right)$ with that same participant's score in writing composition $\left(\mathrm{Y}_{2}\right)$ after receiving $\mathrm{NCCF}\left(\mathrm{X}_{2}\right)$.

The instruments employed in this study were writing tasks i.e. two compositions/texts and the scoring rubric to assess the quality of the students' writing. The students were to write an analytical exposition text by choosing one of the topics provided. The scoring was based on the quality of the content, organization, vocabulary, language use and mechanics. To avoid subjectivity, two raters were called for to measure the rating process.

Since this study focused on the short-term effect of the corrective feedback on the students' writing quality, the students revised their writing immediately in the classroom right after they got the feedback. It took two meeting sessions for experimenting one correction feedback. Table 1 presents the detailed activities for data collection. Since the design of the study was repeated measure, student's t-test for correlated group was used to analyze the results. The statistical computation was administered by using SPSS 16 .

\section{FINDINGS}

The means of both compositions with different feedbacks were compared and analyzed. The mean of the writings with CCF was 82.58, while the mean of the writings with NCCF was 80.80 . The means from both writings (CCF and NCCF) were then analyzed by using t-test for correlated samples. The result of analysis indicated that the difference was significant at .003 level. This result showed that the different kinds of written corrective feedback (CCF and NCCF) given made the quality of the senior high school students' writing significantly different. The quality of the students' writing which received Coded Correction Feedback was better than the quality of students' writing which received NonCoded Correction Feedback. 
In addition to the significant difference in terms of statistics, the substantial difference of the students' writing quality was observed by analyzing the students' works after receiving CCF and NCCF. The substantial difference showed how the feedback affected the quality of writings. The sample of students' work after being given Coded Correction Feedback and Non-Coded Correction Feedback were compared. The sample of revisions from both CCF and NCCF shared some similarities and differences. The quality of content, organization and handwriting of both writings showed slightly significant differences. Both contents were knowledgeable, substantive and relevant to each topic. The points of view of each topic were fairly stated and defended. The organizations were also fluent and sequential. However, differences in terms of sentence structures can be observed from both revisions. Major grammatical errors were less found in student's revision after being given CCF. On the other hand, sample of student's revision after being given NCCF showed more frequent grammatical errors. Moreover, the effects of the major errors impeded the meaning, thus the point of view of the sentences were hardly caught.

Table 1. Meetings for data collection

\begin{tabular}{cll}
\hline Meeting & \multicolumn{1}{c}{ Activities at Class A } & \multicolumn{1}{c}{ Activities at Class B } \\
\hline 1 & $\begin{array}{l}\text { The students wrote composition } 1 \text { in the classroom. } \\
\text { Then, we gave Coded Correction Feedback. }\end{array}$ & $\begin{array}{l}\text { The students wrote composition } 2 \text { in the classroom. } \\
\text { Then, we gave Non-Coded Correction Feedback. }\end{array}$ \\
\hline 2 & $\begin{array}{l}\text { The students got their composition 1 with Coded } \\
\text { Correction Feedback and revised it in the classroom. } \\
\text { The revisions were then documented. }\end{array}$ & $\begin{array}{l}\text { The students got their composition } 2 \text { with Non- } \\
\text { Coded Correction Feedback and revised it in the } \\
\text { classroom. The revisions were then documented. }\end{array}$ \\
\hline 3 & $\begin{array}{l}\text { The students wrote composition } 2 \text { in the classroom. } \\
\text { Then, we gave Non-Coded Correction Feedback. }\end{array}$ & $\begin{array}{l}\text { The students wrote composition 1 in the classroom. } \\
\text { Then, we gave Non-Coded Correction Feedback. }\end{array}$ \\
\hline 4 & $\begin{array}{l}\text { The students got their composition } 2 \text { with Non- } \\
\text { Coded Correction Feedback and revised it in the } \\
\text { classroom. The revisions were then documented. }\end{array}$ & $\begin{array}{l}\text { The students got their composition 1 with Coded } \\
\text { Correction Feedback and revised it in the classroom. } \\
\text { The revisions were then documented }\end{array}$ \\
\hline
\end{tabular}

\section{DISCUSSION}

Several learning theories confirm the positive effects of WCF (see Gagne, 1985; Williams \& Burden, 1997; Krashen, 2003; Brown, 2007). Moreover, a number of previous research studies have also indicated the importance and the effect of corrective feedback (Ashwell, 2000; Ellis et al., 2006; Hong, 2004; Carless, 2006; Sheen, 2007; Bitchener, 2008; Van Beuningen, 2010; Purnawarman, 2011; Ferris \& Roberts, 2001; Ferris, Brown, Liu, \& Stine, 2011; Ferris et al., 2013; Muth'im \& Latief, 2014). This present study can then be considered as giving an additional support to these theories and the previous research studies.

The research findings of this present study confirm the findings of some previous studies in relation to the short term effects of written corrective feedback. When students receive written corrective feedback on a text and are then asked to revise that text, they do so successfully, with "success" being defined as a statistically significant reduction in the numbers of errors as verified by Bitchener \& Ferris (2012). In addition, previous studies in EFL context which supported the effect of written corrective feedback on short term revision involved adults or intermediate learners at a university level as the subjects (see Ferris \& Roberts, 2001; Ashwell, 2000; Truscott \& Hsu, 2008; Hong, 2004; Muth'im \& Latief, 2014). This present research was different in terms of engaging senior high school students as the subjects. The high mean scores gained in their writing revision proved that the senior high school students were able to correct errors on their own. Thus, it can be concluded that the written corrective feedback is effective on short term revision, not only for adults or intermediate learners at a university level, but also for learners at senior high schools.

Considering the differences between CodedCorrection Feedback and Non-Coded Correction Feedback, the finding of this study confirms the study done by Makino (1993), with which he found that more explicit types of teacher error feedback on students' composition resulted in successful selfcorrection on their grammatical errors. The result of this present study is also in line with Ferris et al. (2013) who state that Explicit CF (with labels, codes, or other metalinguistic explanation) may be more valuable for some students than unlabeled $\mathrm{CF}$. Thus the use of Coded-Correction Feedback (CCF) could be considered more effective than Non-Coded Correction Feedback (NCCF).

However, the result of this present study is different from that of Hong (2004) which shows that there is no significant difference in performance on self-correction between Non-Coded Correction Feedback and Coded-Correction Feedback group, although the result of her survey reveals that students prefer receiving CCF rather than NCCF. The discrepancy between this present study and Hong's study may be due to the dependent variable measured. In Hong's study (2004), it was students' self-correction ability, whereas the dependent variable in this present study was students' writing quality. Moreover, Hong attempted to focus on analyzing only five error categories, namely: verbs, 
noun endings, articles, wrong words and sentence structures. On the other hand, this present study focused on five aspects of writing, namely: content, organization, vocabulary, language use and mechanic. As a result of these differences in dependent variable and writing aspects, Hong's findings were different from those of the present study.

There is also a difference between the present study and the study conducted by Muth'im (2013). He implemented three kinds of correction feedback to three different groups, namely sample-end comment (SEC) feedback, coded-correction feedback (CCF) and non-coded correction feedback (NCCF). He found that the three techniques of error correction feedback were equally effective, or none of the three was more effective than the others. The plausible explanation of this discrepancy is because of the differences of subjects and the different use of feedback in the study. The study by Muth'im (2013) was an experimental study which involved 54 English Department students, whereas the present study involved 53 senior high school students. The use of feedback was also different. Muth'im (2013) used feedback as technique of teaching. The feedback was given for three essays written by students consecutively before the final writing the score of which were documented to judge the effect of the feedback. On the other hand, the present study focused on the short term effect of feedback, in which feedback was not used as technique of teaching. The students were asked to write two different compositions and each of them were given CCF and NCCF immediately afterwards. The scores of revision were immediately documented and compared to see the effect.

In addition, the students' mean score on the five aspects of writing after they were given $\mathrm{CCF}$ were higher than that after they given NCCF. However, substantially, the differences are only significant in terms of language use. The plausible explanation of this result can be drawn from studies by Bitchener (2008) and Van Beuningen (2010) which reveal that corrective feedback develops more on accuracy as it offers learner opportunities to notice the gaps in their linguistic systems. Further, it can be argued that the cognitive investment of editing one's text after receiving error feedback is likely a necessary step on the road to longer term improvement in accuracy (Ferris, 2004). In this regard, Purnawarman (2011) also states that corrective feedback is effective in reducing students' grammatical errors. In addition, Truscott and Hsu (2008) acknowledge that correction does help students reduce their grammatical errors on the writing on which they receive the corrections, and that the effect is substantial. In this study, among five writing aspects, grammatical error was covered as an aspect of language use, and handwriting, spelling and punctuation were covered as aspects of mechanic.

\section{CONCLUSION}

The quality of the students' writing which received Coded Correction Feedback is better than the quality of students' writing which received Non-Coded Correction Feedback because Coded Correction Feedback promotes awareness with, not only noticing, but also understanding. Hence, the use of Coded-Correction Feedback (CCF) can be considered more effective than Non-Coded Correction Feedback (NCCF). In addition, Coded Correction Feedback (CCF) works effectively in terms of language use and mechanic. Coded Correction Feedback develops more on accuracy and it is effective in reducing students' grammatical errors. Hence, the quality of language use and mechanic of students' writing after being given Coded Correction Feedback (CCF) is better than after being given Non-Coded Correction Feedback.

Based on the result of the study, English teachers can employ Coded-Correction Feedback for checking their students' writing composition. Research dealing with the effects of written corrective feedback, specifically on content, organization or vocabulary, writing accuracy, and grammatical errors may need to be conducted investigating both the short term and long term effects.

\section{REFERENCES}

Ashwell, T. (2000). Patterns of teacher response to student writing in a multiple-draft composition classroom: Is content feedback followed by form feedback the best method? Journal of Second Language Writing, 9 (3), 227-258.

Baker, W., \& Bricker, R. H. (2010). The effects of direct and indirect speech acts on native English and ESL speakers' perception of teacher written feedback. System, 38, 75-84. http://dx.doi.org/10.1016/j.system.2009.12.007. In M. Thurlings et al./Educational Research Review 9 (2013) 1-15 Retrieved February 26, 2017 from http://purl.tue.nl/42228237280279.pdf

Bitchener, J. \& Ferris, D.R. (2012). Written corrective feedback in second language acquisition and writing. New York: Routledge.

Bitchener, J. (2008). Evidence in support of written corrective feedback. Journal of Second Language Writing, (Online), 17 (1): 102-118). Retrieved August 18, 2015 from http://www.jimelwood.net/students/grips/tables _figures/bitchener_2008.pdf

Brown, H.D. (2007). Teaching by principles: An interactive approach to language pedagogy. USA: Pearson Education, Inc. 
Carless, D. (2006). Differing perceptions in the feedback process. Studies in Higher Education, (Online), 31(2): 219-233. Retrieved August 18, 2015 from

http://www.victoria.ac.nz/education/pdf/davidcarless.pdf.

Ellis, R., Loewen, S., \& Erlam, R. (2006). Implicit and explicit corrective feedback and the acquisition of L2 grammar. Studies in Second Language Acquisition. 28(2), 339-368.

Ferris, D.R. \& Roberts, B.J. (2001). Error feedback in L2 writing classes: How explicit does it need to be? Journal of Second Language Writing, 10(3), 161-184.

Ferris, D.R. (2004). The "grammar correction" debate in L2 writing: Where are we, and where do we go from here? (and what do we do in the meantime . . .?). Journal of Second Language Writing, 13(1), 49-62, (Online), (http://citeseerx.ist.psu.edu/viewdoc/download ?doi=10.1.1.110.4148\&rep=rep1\&type=pdf), accessed on May 6, 2016.

Ferris, D.R., Brown, J., Liu, H., \& Stine, M.E.A. (2011). Responding to L2 writers in college writing classes: Teacher perspectives. TESOL Quarterly, 45(2), 207-234. doi: $10.5054 /$ tq. 2011.247706

Ferris, D.R., Liu, H. Sinha, A., \& Senna, M. (2013). Written corrective feedback for individual L2 writers. Journal of Second Language Writing. 22 (3): 307-329.

Gagne, R. (1985). Conditions of learning. (Online). Retrieved February 24, 2015 from http:// tip.psychology.org/gagne.html.

Gielen, S., Peeters, E., Dochy, F., Onghena, P., \& Struyven, K. (2010). Improving the effectiveness of peer feedback for learning. Learning and Instruction, 20(4), 304-315. http://dx.doi.org/10.1016/j.learninstruc. 2009.0 8.007. In M. Thurlings et al./Educational Research Review 9 (2013) 1-15 Retrieved February 26, 2017 from http://purl.tue.nl/42228237280279.pdf

Hong, Y. (2004). The effect of teachers' error feedback on international students' selfcorrection ability. Online Master Thesis. Utah: Department of Linguistics and English Language Brigham Young University, (Online). Retrieved September 8, 2015 from http://scholarsarchive.byu.edu/cgi/viewcontent. cgi? article $=1182 \&$ context $=$ etd.

Krashen, S.D. (2003). Explorations in language acquisition and use: The Taipei lectures. Portsmouth, NH: Heinemann.

Li, L., Liu, X., \& Steckelberg, A. L. (2010). Assessor or assessee: How student learning improves by giving and receiving peer feedback. British Journal of Educational
Technology, 41(3), 525-536.

http://dx.doi.org/10.1111/j.1467-

8535.2009.00968.x

Makino, T. (1993). Learner self-correction in EFL written compositions. ELT Journal, 47(4), 337341.

Muth'im, A., \& Latief, M. A. (2014). The effectiveness of indirect error correction feedback on the quality of students' writing. Arab World English Journal, 5(2), 244-257. Retrieved August 25, 2015 from http://www.awej.org/images/AllIssues/Volume 5/Volume5Number2June2014/19.pdf.

Muth'im, A. (2013). The effect of indirect error correction feedback on the quality of students' writing (Unpublished Doctoral Dissertation). State University of Malang, Malang, Indonesia

Purnawarman, P. (2011). Impacts of different types of teacher corrective feedback in reducing grammatical errors on ESL/EFL students' writing (Doctoral Dissertation, Virginia Polytechnic Institute and State University, Blacksburg, Virginia, The United States of America). Retrieved on August 18, 2015 from http://scholar.lib.vt.edu/theses/available/etd 12122011211734/unrestricted/Purnawarman_P _Dissertation_2011.pdf.

Sheen, Y. (2007). The effect of focused written corrective feedback and language aptitude on ESL learners' acquisition of articles. TESOL Quarterly, 41(2), 255-283.

Truscott, J. \& Hsu, A.Y-P. (2008). Error correction, revision, and learning. Journal of Second Language Writing, 17 (4), 292-305.

Van Beuningen, C. (2010). Corrective feedback in L2 writing: Theoretical perspectives, empirical insights, and future directions. International Journal of English Studies, 10(2), 1-27. Retrieved August 18, 2015 from http://revistas.um.es/ijes/article/viewFile/1191 71/112301. In M. Thurlings et al./Educational Research Review 9 (2013) 1-15 Retrieved February 26, 2017 from http://purl.tue.nl/42228237280279.pdf

Van Beuningen, C. G., De Jong, N. H., \& Kuiken, F. (2012). Evidence on the effectiveness of comprehensive error correction in second language writing. Language learning, 62(1), 141. http://dx.doi.org/10.1111/j.14679922.2011.00674.x. In M. Thurlings et al./Educational Research Review 9 (2013) 115 Retrieved February 26, 2017 from http://purl.tue.nl/42228237280279.pdf

Williams, M. \& Burden, R.L. (1997). Psychology for language teachers: A social constructivist approach. Cambridge: Cambridge University Press. 